\title{
Ethylene tetramerization with a highly active and long-lifetime trinuclear diphenylphosphinoamine/Cr(III)/MAO catalyst
}

\author{
JIANG Tao $^{1,2^{*}}$, TAO YiQing ${ }^{1}$, GAO XiangLu ${ }^{1}$, MAO GuoLiang $^{2}$, CHEN HongXia $^{1}$, \\ CAO ChenGang ${ }^{1} \&$ NING YingNan ${ }^{2}$ \\ ${ }^{1}$ College of Material Science and Chemical Engineering, Tianjin University of Science \& Technology, Tianjin 300457, China; \\ ${ }^{2}$ Department of Chemistry and Chemical Engineering, Northeast Petroleum University, Daqing 163318, China
}

Received June 26, 2011; accepted November 19, 2011; published online March 12, 2012

\begin{abstract}
The synthesis and characterization of a novel trinuclear diphosphinoamine ligand $\mathbf{2}$ are reported. The ligand combined with $\mathrm{Cr}(\mathrm{IIII})$, activated with methylaluminoxane, lead to highly active and long-lifetime catalytic systems for the tetramerization of ethylene to form 1-octene. The effects of reaction temperature, reaction pressure, molar ratio of $\mathrm{Al} / \mathrm{Cr}$ and bis(diphenylphosphino)amine/Cr on the catalytic activity and product selectivity were studied. Compared with its mononuclear analogue 1, ligand 2 showed a higher catalytic activity and longer lifetime for ethylene tetramerization in the presence of methylaluminoxane as cocatalyst. High molecular weight polyethylene was generated as a by-product with extremely broad molecular weight distributions.
\end{abstract}

ethylene tetramerization, 1-octene, trinuclear, diphenylphosphinoamine

Citation: Jiang T, Tao Y Q, Gao X L, et al. Ethylene tetramerization with a highly active and long-lifetime trinuclear diphenylphosphinoamine/Cr(III)/MAO catalyst. Chin Sci Bull, 2012, 57: 1510-1515, doi: 10.1007/s11434-012-5032-3

In recent years there has been a substantial acceleration in research activity concerned with homogeneous transition metal catalysts for ethylene oligomerization and polymerization. Chromium catalysts play an important role in both of these processes [1-8]. Since the first report of ethylene tetramerization to form 1-octene using Cr-bis(diphenylphosphino)amine (PNP) catalysts [9], numerous studies have investigated the relationship between ligand structure and catalytic properties. These include investigations into various single-site PNP ligands, wherein alkyl [10-12], cycloalkyl [13], ether [14], thioether, pyridyl tethers [15] and aryl $[16,17]$ substituents attached to the $\mathrm{N}$ or $\mathrm{P}$ atom of the ligand backbone were synthesized and evaluated. Several dual-site PNP ligands [12,18] and a triple-site [19] were also found to have moderate activity and selectivity toward 1-octene in ethylene tetramerization.

We were attracted by the potential for using chromium as an ethylene tetramerization active center because of its high

*Corresponding author (email: jiangtao@tust.edu.cn) catalytic activity and high selectivity to 1-octene. Here, we describe a new trinuclear PNP ligand that displays higher activity and a long lifetime for ethylene tetramerization to 1-octene.

\section{Experimental}

All manipulations of water and/or moisture sensitive compounds were performed by means of standard high-vacuum Schlenk techniques under a $\mathrm{N}_{2}$ atmosphere. Toluene was refluxed and distilled from sodium/benzophenone under dry nitrogen. The ligand $\mathbf{1}$ was prepared according to a published procedure [9]. Cis, cis-1,3,5-cyclohexanetricarboxylic acid, diphenylphosphoryl azide(DPPA) and $\mathrm{Cr}(\mathrm{acac})_{3}$ were purchased from Sigma-Aldrich(Pennsylvania, USA) and used as received. Polymerization grade ethylene was obtained from Daqing Petro-Chemical Ltd. (Daqing, China). Methylaluminoxane (MAO) solution $(1.4 \mathrm{~mol} / \mathrm{L})$ in toluene was purchased from Albemarle Corp. (Louisiana, USA). Cyclohexane, toluene and ethanol were dehydrated and de- 
gassed before use. All other chemicals were obtained commercially and used as received.

\subsection{Preparation and characterization of the ligand}

The synthesis method of trinuclear PNP ligand $\mathbf{2}$ is described in Figure 1. Cis,cis-1,3,5-triaminocyclohexane was prepared from commercially available cis, cis-1,3,5-cyclohexanetricarboxylic acid according to a procedure published previously [20]. Trinuclear PNP ligand 2 was synthesized through the reaction between cis,cis-1,3,5-triaminocyclohexane and diphenylphosphine chloride according to a method described in the literature [9].

(1) Preparation of cis,cis-1,3,5-triaminocyclohexane. Cis, cis-1,3,5-cyclohexanetricarboxylic acid (2.0 g, $9.2 \mathrm{mmol})$ was washed into a round-bottomed flask with toluene $(75 \mathrm{~mL})$ and Et3N (3.9 mL, $28 \mathrm{mmol}$ ) was added followed by DPPA (7.7 $\mathrm{g}, 28 \mathrm{mmol})$. The mixture was stirred for $0.5 \mathrm{~h}$ at room temperature and then refluxed for $0.5 \mathrm{~h}$. Benzyl alcohol (3.34 g, $30.88 \mathrm{mmol}$ ) was added and the solution was refluxed for $18 \mathrm{~h}$, during which a precipitate formed. After cooling to ambient temperature, the product was collected by vacuum filtration, washed with minimal cold toluene, and dried under vacuum to leave $2.47 \mathrm{~g}(75.8 \%) .{ }^{1} \mathrm{H} \operatorname{NMR}(\delta$, $\left.\mathrm{CDCl}_{3}, \mathrm{TMS}\right): \delta 7.37-7.20(\mathrm{~m}, 5 \mathrm{H}), 5.0(\mathrm{~s}, 2 \mathrm{H}), 3.39(\mathrm{~m}$, $1 \mathrm{H}), 1.90$ (d, 1H). EI-MS $(\mathrm{m} / \mathrm{z})$ 532. Anal. Calcd. for $\mathrm{C}_{30} \mathrm{H}_{33} \mathrm{~N}_{3} \mathrm{O}_{6}(\%)$ : C, 67.77; H, 6.27; N, 7.91. Found (\%): C, $67.71 ; \mathrm{H}, 6.25 ; \mathrm{N}, 8.06$. The $\mathrm{CBZ}$ groups were most efficiently cleaved by treatment of the solid directly with $33 \%$ $\mathrm{HBr} / \mathrm{HOAc}$. Shortly after a clear solution was achieved, a thick suspension formed, which was diluted with an equal volume of anhydrous ether to ease filtration. The product was collected and dried, providing the desired triamine as a solid. ${ }^{1} \mathrm{H}$ NMR $\left(\delta, \mathrm{CDCl}_{3}, \mathrm{TMS}\right): \delta 0.83-0.95(\mathrm{~m}, 3 \mathrm{H})$, 1.00-1.40 (br, 6H), 1.90-2.06 (m, 3H), 2.70-2.85 (m, 3H).

(2) Preparation of trinuclear diphenylphosphinoamine.
To a solution of the bis(phenyl)phosphorus chloride (1.33 $\mathrm{mL}, 7.2 \mathrm{mmol})$ in dichloromethane $(20 \mathrm{~mL})$ and triethylamine $(3.75 \mathrm{~mL})$ at $0^{\circ} \mathrm{C}$, cis,cis-1,3,5-triaminocyclohexane $(0.155 \mathrm{~g}, 1.2 \mathrm{mmol})$ was added. It was stirred for $30 \mathrm{~min}$ and then the ice bath was removed. After stirring for a total of $14 \mathrm{~h}$, the solution was filtered to remove the triethylammonium salt formed. The product was isolated after crystallization in $65 \%$ yield. ${ }^{1} \mathrm{H}$ NMR $\left(\delta, \mathrm{CDCl}_{3}, \mathrm{TMS}\right): \delta$ $1.46-1.55(\mathrm{~m}, 3 \mathrm{H}), 2.69-2.78(\mathrm{~m}, 3 \mathrm{H}), 2.85-2.93(\mathrm{~m}, 3 \mathrm{H})$, 6.82-7.65 (m, 60H). Anal. calcd. for $\mathrm{C}_{78} \mathrm{H}_{69} \mathrm{~N}_{3} \mathrm{P}_{6}(\%)$ : $\mathrm{C}$, 75.90; H, 5.63; N, 3.40. Found (\%): C, 76.15; H, 5.41; N, 3.62. EI-MS $(70 \mathrm{eV}): \mathrm{m} / \mathrm{z}=1233$. Coordination of the ligand to the $\mathrm{Cr}$ (III) metal center was indicated by the immediate color change of the reaction mixture from pink to dark blue. Unfortunately, crystals suitable for X-ray structure determination were not obtained by recrystallization in $\mathrm{CH}_{2} \mathrm{Cl}_{2}$ / hexane system. Because of the strong paramagnetic nature of the octahedral $\mathrm{d} 3 \mathrm{Cr}$ (III) center, complexes are silent in ${ }^{31} \mathrm{P}$ NMR and their ${ }^{1} \mathrm{H}$ and ${ }^{13} \mathrm{C}$ NMR spectra exhibited only broad signals that could not be exploited to establish their structure. Therefore, the complexes were primarily characterized by elemental analysis data.

\subsection{Ethylene tetramerization}

Ethylene tetramerization was processed in a $500 \mathrm{~mL}$ autoclave. After evacuation and flushing with nitrogen three times and then twice with ethylene, the autoclave was charged with $200 \mathrm{~mL}$ solvent and magnetically stirred under an ambient ethylene atmosphere. When the desired reaction temperature was established, the required amount of ligand, $\mathrm{Cr}$ (III) and MAO were injected into the reactor. Typically, $30 \mathrm{~min}$ later, the reaction solution was quickly cooled to $5^{\circ} \mathrm{C}$ and then quenched by adding $\mathrm{HCl} /$ ethanol $(10 \mathrm{wt} \%$ ). The catalytic activity was calculated based on the increase in product weight. The distribution of tetramerization product

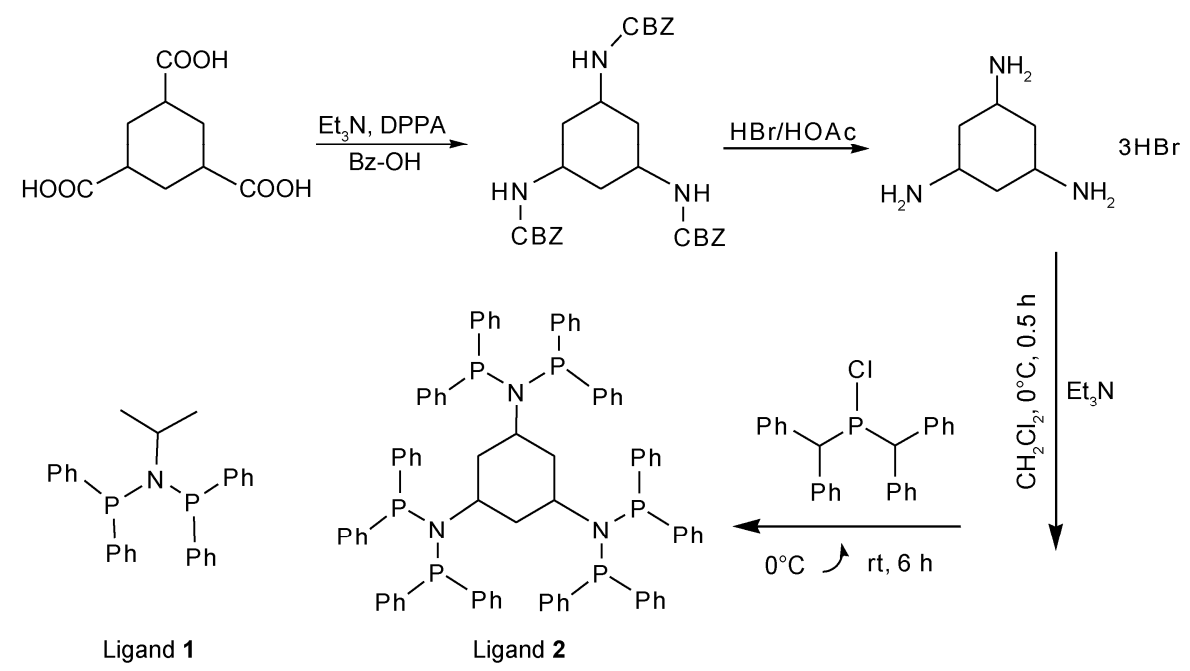

Figure 1 Synthesis of trinuclear PNP precatalyst 2. 
was analyzed by GC-MS, while the precipitated polymer was collected by filtration, washed with ethanol, dried under vacuum at $60^{\circ} \mathrm{C}$ to constant weight, weighed, and finally characterized.

\subsection{Characterization of product}

A small liquid sample was washed by deionized water to remove alcohol, MAO and hydrochloric acid. The organic layer was then dried over anhydrous sodium carbonate and analyzed by an HP-5890 GC-MS instrument equipped with an HP-1 capillary column $(30 \mathrm{~m} \times 0.25 \mathrm{~mm})$ and an HP-5971 mass spectroscope, at $35^{\circ} \mathrm{C}(10 \mathrm{~min})$ and then heated at $10^{\circ} \mathrm{C} / \mathrm{min}$ until reaching $280^{\circ} \mathrm{C}$ (remaining for 10 $\mathrm{min})$. The molecular weight and its distribution of polymers were determined by gel permeation chromatography (GPC) on a Waters Alliance GPCV2000 at $150^{\circ} \mathrm{C}$ with $1,2,4-$ trichlorobenzene as eluent. Melting points of polymers were measured on a Perkin-Elmer DSC-7 in the standard DSC run mode.

\section{Results and discussion}

\subsection{The effect of reaction temperature on catalytic properties}

As shown in Table 1, the catalytic activity and product distribution were strongly affected by reaction temperature. Elevating the reaction temperature from 30 to $70^{\circ} \mathrm{C}$, the catalytic activity increased initially with temperature and reached a maximum around $40^{\circ} \mathrm{C}$. As reaction temperature increases from 40 to $70^{\circ} \mathrm{C}$, a sharp decrease in productivity was observed. Higher temperatures can result in lower ethylene solubility and higher rates of catalyst deactivation, which can lead to reduced productivity. The results of the temperature study reveal considerable changes in the product distribution with temperature variation, showing an increasing trend in selectivity to 1-hexene and a decreasing trend in selectivity to 1-octene with increasing reaction temperature. In terms of the reaction mechanism [21], it can be concluded that at higher temperatures, the reductive elimination of 1-hexene is favored over $\beta$-hydride transfer to chromium. Noteworthy by-products of this reaction include methylcyclopentane and methylenecyclopentane (at an almost 1:1 ratio). These cyclic by-products had the adverse effect of decreasing the total alpha selectivity and the loss of valuable ethylene feedstock led to further efforts aimed at reducing these unwanted products.

\subsection{The effect of $\mathrm{Al} / \mathrm{Cr}$ molar ratios on catalytic properties}

The effect of the $\mathrm{Al} / \mathrm{Cr}$ molar ratio on ethylene tetramerization was investigated in detail with ligand $\mathbf{2}$, the results are listed in Table 2. A higher productivity was obtained at a ratio of 300. Decomposition of catalyst complex at higher MAO loading may explain the decrease in catalytic activity [22]. Contrary to the results reported previously [23], an increase in the $\mathrm{Al} / \mathrm{Cr}$ molar ratio from 100 to 500 resulted in an increase in selectivity to 1 -octene. The same results were found in the tetramerization of ethylene with triple-site diphosphinoamine (PNP)/Cr(III)/MAO[19].

Table 1 Effects of reaction temperature on catalytic activity and product distribution ${ }^{\text {a) }}$

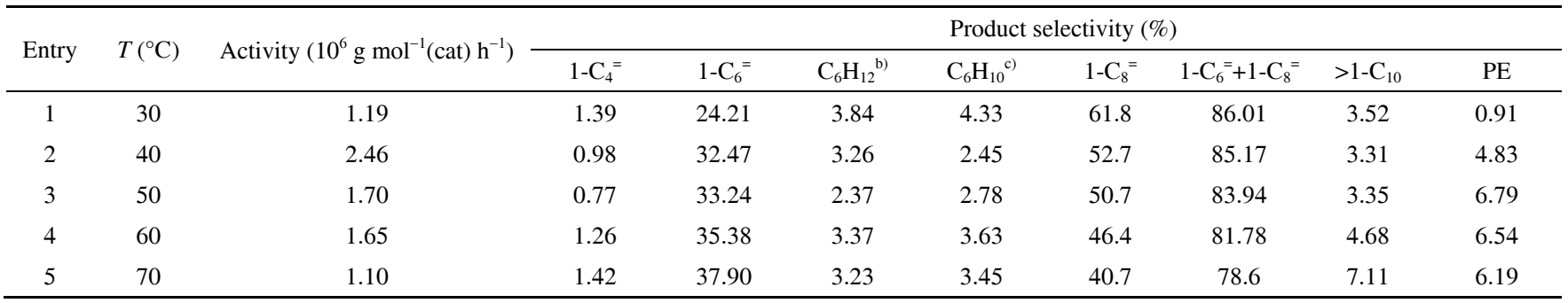

a) Solvent: cyclohexane; reaction pressure: $2.0 \mathrm{MPa} ; 2: \mathrm{Cr}(\mathrm{III}): \mathrm{MAO}=1: 3: 900$; reaction time: $30 \mathrm{~min}$. b) Methylcyclopentane. c) Methylenecyclopentane.

Table 2 Effects of $\mathrm{Al} / \mathrm{Cr}$ molar ratio on catalytic activity and product distribution ${ }^{\text {a) }}$

\begin{tabular}{|c|c|c|c|c|c|c|c|c|c|c|}
\hline \multirow{2}{*}{ Entry } & \multirow{2}{*}{$\mathrm{Al} / \mathrm{Cr}$} & \multirow{2}{*}{ Activity $\left(10^{6} \mathrm{~g} \mathrm{~mol}^{-1}(\mathrm{cat}) \mathrm{h}^{-1}\right)$} & \multicolumn{8}{|c|}{ Product selectivity $(\%)$} \\
\hline & & & $1-\mathrm{C}_{4}=$ & $1-\mathrm{C}_{6}=$ & $\mathrm{C}_{6} \mathrm{H}_{12}{ }^{\mathrm{b})}$ & $\mathrm{C}_{6} \mathrm{H}_{10}{ }^{\mathrm{c})}$ & $1-\mathrm{C}_{8}=$ & $1-\mathrm{C}_{6}{ }^{=}+1-\mathrm{C}_{8}=$ & $>1-\mathrm{C}_{10}$ & $\mathrm{PE}$ \\
\hline 6 & 100 & 1.98 & 0.83 & 31.22 & 3.16 & 3.38 & 53.81 & 85.03 & 4.32 & 3.28 \\
\hline 7 & 200 & 2.30 & 1.10 & 30.53 & 3.22 & 3.65 & 54.02 & 84.55 & 3.98 & 3.50 \\
\hline 2 & 300 & 2.46 & 0.98 & 32.47 & 3.26 & 2.45 & 52.70 & 85.17 & 3.31 & 4.83 \\
\hline 8 & 400 & 1.79 & 1.02 & 29.87 & 3.00 & 3.27 & 55.90 & 85.77 & 2.58 & 4.36 \\
\hline
\end{tabular}

a) Solvent: cyclohexane; reaction pressure: $2.0 \mathrm{MPa} ; \mathrm{Cr}(\mathrm{III}): 2=3: 1$; reaction time: 30 min; reaction temperature: $40^{\circ} \mathrm{C}$. b) $\mathrm{Methylcyclopentane}$. c) Methylenecyclopentane. 


\subsection{The effect of reaction pressure on catalytic proper- ties}

The effects of reaction pressure on catalytic properties are shown in Table 3. An elevated ethylene pressure led to an increase in the ethylene concentration in the solvent, resulting in an increase in the chain propagation rate and thus inducing increased catalytic activity. The selectivity to 1-hexene decreased and the selectivity to 1-octene increased with increasing ethylene pressure. Changes in product distribution were in good agreement with the metallacycle mechanism proposed by Overett et al. [24]. This is indicative of a strong ethylene concentration influence on the product distribution in general and the formation of 1octene in particular.

\subsection{The dynamic behavior of the catalytic systems}

The kinetic profiles of ethylene tetramerization using ligand 1/Cr(III)/MAO and ligand 2/Cr(III)/MAO were investigated by measuring the flow rate of ethylene into the reactor with a mass flowmeter. The effect of catalyst lifetime on catalytic activity is shown in Figure 2. The high ethylene flow rate during the first $4 \mathrm{~min}$ of reaction reflects the process of ethylene saturation in the solvent.

The rate profile of ligand $\mathbf{1}$ exhibits typical decay kinetics, with a very high initial rate followed by a rapid decay. The attenuation rate of the catalytic activity of ligand $\mathbf{1}$ was much faster than that of ligand 2 . The catalytic activity of ligand 2 was found to remain constant up to $60 \mathrm{~min}$, followed by a laggard attenuation. Hence, ligand $\mathbf{2}$ exhibited much higher catalytic activity than ligand $\mathbf{1}$ with polymerization time, which indicates that the trinuclear can restrain the chromium catalytic active center from deactivation [22].

\subsection{Characterization of polyethylene}

Noteworthy by products of this reaction include polyeth-

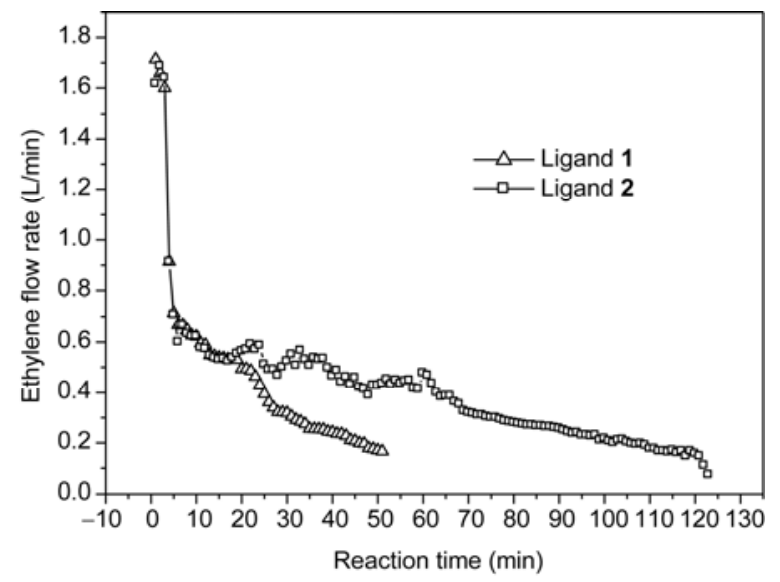

Figure 2 Kinetic profiles of ethylene tetramerization using ligands $\mathbf{1}$ and 2 with $\mathrm{Cr}(\mathrm{III})$ and MAO. Reaction pressure: $3.0 \mathrm{MPa}$; reaction temperature: $40^{\circ} \mathrm{C} ; \mathrm{Al} / \mathrm{Cr}$ ratio: 300

Table 3 Effects of reaction pressure on catalytic activity and product distribution ${ }^{\text {a) }}$

\begin{tabular}{|c|c|c|c|c|c|c|c|c|c|c|}
\hline \multirow{2}{*}{ Entry } & \multirow{2}{*}{$P(\mathrm{MPa})$} & \multirow{2}{*}{ Activity $\left(10^{6} \mathrm{~g} \mathrm{~mol}^{-1}(\right.$ cat $\left.) \mathrm{h}^{-1}\right)-$} & \multicolumn{8}{|c|}{ Product selectivity (\%) } \\
\hline & & & $1-\mathrm{C}_{4}=$ & $1-C_{6}=$ & $\mathrm{C}_{6} \mathrm{H}_{12}{ }^{\mathrm{b})}$ & $\mathrm{C}_{6} \mathrm{H}_{10}{ }^{\mathrm{c})}$ & $1-\mathrm{C}_{8}=$ & $1-\mathrm{C}_{6}{ }^{=}+1-\mathrm{C}_{8}=$ & $>1-\mathrm{C}_{10}$ & $\mathrm{PE}$ \\
\hline 2 & 2.0 & 2.46 & 0.98 & 32.47 & 3.26 & 2.45 & 52.7 & 85.17 & 3.31 & 4.83 \\
\hline 10 & 3.0 & 4.79 & 1.08 & 26.94 & 3.08 & 3.00 & 57.7 & 84.64 & 3.20 & 5.00 \\
\hline 11 & 4.0 & 9.45 & 0.99 & 24.99 & 2.91 & 3.24 & 58.8 & 83.79 & 3.78 & 5.29 \\
\hline
\end{tabular}

a) Solvent: cyclohexane; $2: \mathrm{Cr}(\mathrm{III}): \mathrm{MAO}=1: 3: 900$; reaction time: $30 \mathrm{~min}$; reaction temperature: $40^{\circ} \mathrm{C}$. b) Methylcyclopentane. c) Methylenecyclopentane.

Table 4 Characterization of polyethylenes

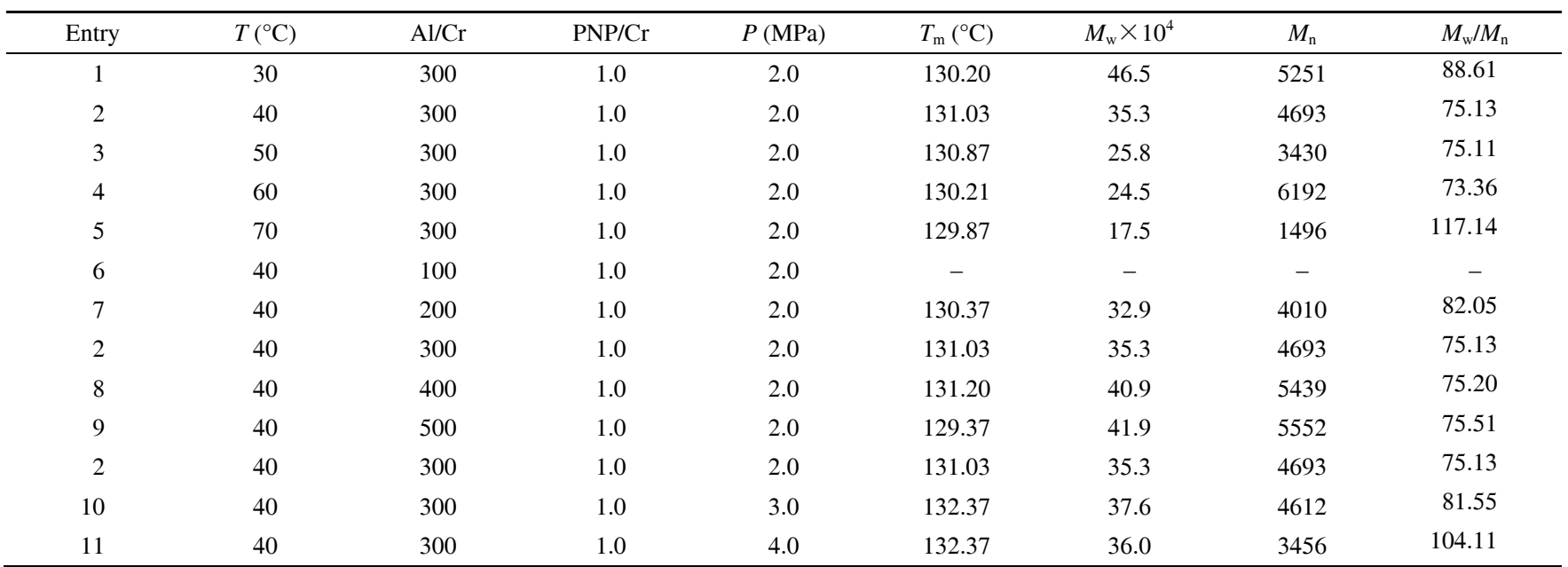


ylene (PE). This phenomenon not only poses an undesired pathway for ethylene transformation, but in a continuous polymer formation process, would lead to uncontrollable reactor fouling, preventing proper reaction heat removal and ultimately leading to the shut-down of the process. A somewhat increased polymer formation compared to its mononuclear ligand $\mathbf{1}$. The polymeric fraction can be ascribed most probably to the very low solubility of the trinuclear complex in cyclohexane solvents. As shown from Table 4, the polymer produced was found to be high molecular weight polyethylene with an average molecular weight distribution larger than 70 . The melting points $\left(T_{\mathrm{m}}\right)$ of the resultant PEs revealed that only one melting peak appeared and the melting temperature was at about $130^{\circ} \mathrm{C}$ for each product.

The molecular weights of the resulting polymers decreased with increasing reaction temperature. The molecular weight of resulting polymers increased with increasing $\mathrm{Al} / \mathrm{Cr}$ molar ratio. This result is in disagreement with that reported for $\mathrm{Fe}(\mathrm{II}), \mathrm{Co}$ (II) and $\mathrm{Cr}$ (III) catalysts [25,26]. The molecular weights of the resulting polymers increased with increasing $\mathrm{Al} / \mathrm{Cr}$ ratio, so there is probably no chain transfer to aluminum in the $2 / \mathrm{Cr}(\mathrm{III}) / \mathrm{MAO}$ catalytic system for the tetramerization of ethylene.

High temperature ${ }^{13} \mathrm{C}$ NMR spectroscopy for the PE sample listed in entry 3 of Table 4 was also performed (Figure 3). The NMR spectrum of polyethylene presented in Figure 3 is in good agreement with a highly linear polyethylene.

\section{Conclusion}

A novel trinuclear diphosphinoamine ligand was synthesiz-

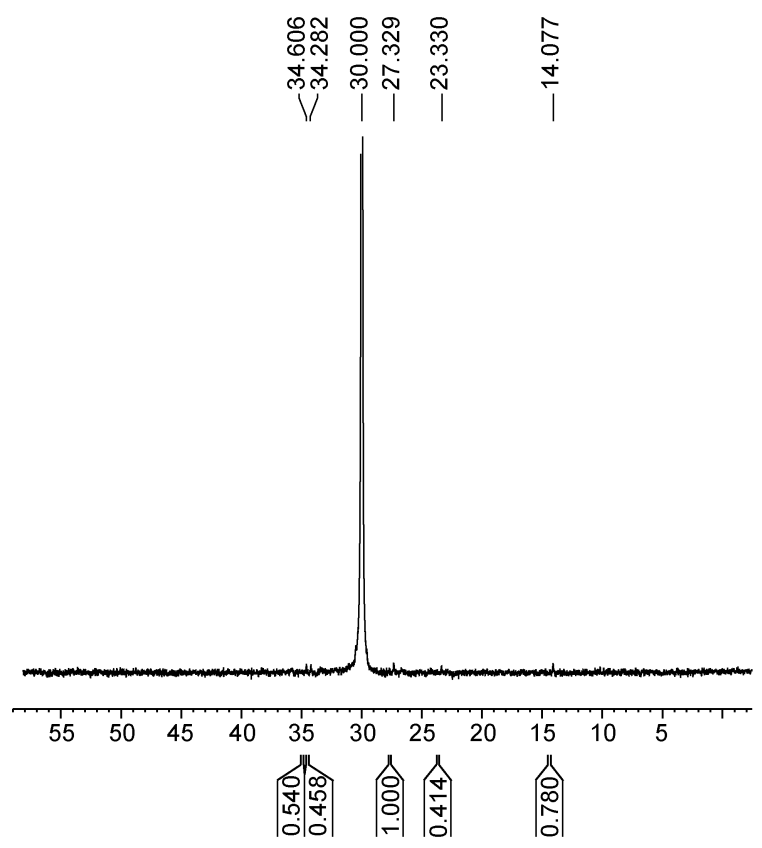

Figure $3{ }^{13} \mathrm{C}$ NMR spectra of PE byproducts. ed and characterized. The ligand combined with $\mathrm{Cr}(\mathrm{III})$ and activated with methylaluminoxane (MAO), produced highly active and long-lifetime catalytic systems for the tetramerization of ethylene to 1-octene. High molecular weight polyethylene was generated as by-product with extremely broad molecular weight distributions. The molecular weights of the resulting polymers increased with increasing $\mathrm{Al} / \mathrm{Cr}$ ratio. There was probably no chain transfer to aluminum in the 2/Cr(III)/MAO catalytic system for the tetramerization of ethylene.

We thank Dr. Zhi Ma for helpful discussions. This work was supported by the National Natural Science Foundation of China (U1162114) and the Program for New Century Excellent Talents in University and the Program for New Century Excellent Talents in Heilongjiang Provincial University (NCET-06-010) and the Science Foundation of Tianjin University of Science \& Technology (20090420).

1 Wang D, Liu S, Sun W, et al. 2-Benzimidazolyl-N-phenylquinoline-8-carboxamide Chromium(III) trichlorides: Synthesis and supplication for ethylene oligomerization and polymerization. Organometallics, 2011, 30: 3001-3009

2 Gao R, Liang T, Wang F, et al. Chromium (III) complexes bearing 2-benzoxazolyl-6-arylimino-pyridines: Synthesis and their ethylene reactivity. J Organomet Chem, 2009, 694: 3701-3707

3 Zhang M, Wang K, Sun W. Chromium(III) complexes bearing 2-benzazole-110-phenanthrolines: Synthesis molecular structures and ethylene oligomerization and polymerization. Dalton Trans, 2009, 6354-6363

4 Saliu A, Amolegbe M, Zhang M, et al. Synthesis characterization and ethylene oligomerization and polymerization by 2-quinoxalinyl-6iminopyridine chromium chlorides. Austr J Chem, 2008, 61: 397-403

5 Chen Y J, Zuo W W, Hao P, et al. Chromium(III) complexes ligated by 2-(1-isopropyl-2-benzimidazolyl)-6-(1-(arylimino)ethyl)pyridines: Synthesis characterization and their ethylene oligomerization and polymerization. J Organomet Chem, 2008, 693: 750-762

6 Yang Y, Liu Z, Zhong L, et al. Spin surface crossing between chromium(I)/sextet and chromium(III)/quartet without deprotonation in SNS-Cr mediated ethylene trimerization. Organometallics, 2011, 19: 5297-5302

7 Qiu P Y, Cheng R H, Liu B P, et al. A triphenylsiloxy complex of chromium(II) as a switchable catalyst for ethylene polymerization and nonselective oligomerization. Organometallics, 2011, 30: 21442148

8 Qi Y, Dong Q, Zhong L, et al. Role of 1,2-dimethoxyethane in the transformation from ethylene polymerization to trimerization using chromium tris(2-ethylhexanoate)-based catalyst system: A DFT study. Organometallics, 2010, 29: 1588-1602

9 Bollmann A, Blann K, Dixon J, et al. Ethylene tetramerization: A new route to produce 1-Octene in exceptionally high selectivities. J Am Chem Soc, 2004, 126: 14712-14713

10 Blann K, Bollmann A, Dixon J, et al. Highly selective chromium based ethylene trimerisation catalysts with bulky diphosphinoamine ligands. Chem Commun, 2005, 5: 620-621

11 Overett M, Blann K, Bollmann A, et al. Ethylene trimerisation and tetramerisation catalysts with polar-substituted diphosphinoamine ligands. Chem Commun, 2005, 5: 622-624

12 Blann K, Bollmann A, Bod H, et al. Ethylene tetramerisation: Subtle effects exhibited by $N$-substituted diphosphinoamine ligands. J Catalys, 2007, 249: 242-247

13 Kuhlmann S, Blann K, Bollmann A, et al. N-substituted diphosphinoamines: Toward rational ligand design for the efficient tetramerization of ethylene. J Catalys, 2007, 245: 279-284

14 Elowe P, McCann C, Pringle P, et al. Nitrogen-linked diphosphine 
ligands with ethers attached to nitrogen for chromium-catalyzed ethylene tri- and tetramerizations. Organometallics, 2006, 25: 52555260

15 Weng Z, Teo S, Hor T. Chromium(III) catalysed ethylene tetramerization promoted by bis(phosphino)amines with an $\mathrm{N}$-functionalized pendant. Dalton Trans, 2007, 23: 3493-3498

16 Killian E, Blann K, Bollmann A, et al. The use of bis(diphenylphosphino)amines with $N$-aryl functionalities in selective ethylene tri- and tetramerisation. J Mol Catal A: Chem, 2007, 270: 214-218

17 Jiang $\mathrm{T}$, Zhang $\mathrm{S}$, Jiang $\mathrm{X}$, et al. The effect of $\mathrm{N}$-aryl bisphosphineamine ligands on the selective ethylene tetramerization. J Mol Catal A: Chem, 2008, 279: 90-93

18 Jiang T, Chen H, Ning Y, et al. Preparation of 1-octene by ethylene tetramerization with high selectivity. Chin Sci Bull, 2006, 51: 521523

19 Mao G, Ning Y, Hu W, et al. Synthesis of a novel triple-site diphosphinoamine(PNP) ligand and its applications in ethylene tetramerization. Chin Sci Bull, 2008, 53: 3511-3515

20 Tom B, Roy P, Martin W. An improved synthesis of cis,cis-1,3,5triaminocyclohexane. Synthesis of novel hexadentate ligand derivatives for the preparation of gallium radiopharmaceuticals. Bioorgan Medic Chem Lett, 1996, 6: 807-810
21 Kim S, Kim J, Chung J, et al. Bimetallic ethylene tetramerization catalysts derived from chiral DPPDME ligands: Syntheses, structural characterizations, and catalytic performance of [(DPPDME) $\left.\mathrm{CrCl}_{3}\right]_{2}$ (DPPDME = S,S- and R,R-chiraphos and meso-achiraphos). Organometallics, 2010, 29: 5805-5811

22 Jabri A, Temple C, Crewdson P, et al. Role of the metal oxidation state in the SNS-Cr catalyst for ethylene trimerization: Isolation of diand trivalent cationic intermidiates. J Am Chem Soc, 2006, 128: 9238-9247

23 Jiang T, Ning Y, Zhang B, et al. Preparation of 1-octene by the selective tetramerization of ethylene. J Mol Catal A: Chem, 2006, 259: $161-165$

24 Overett M, Blann K, Bollmann A, et al. Mechanistic investigations of the ethylene tetramerisation reaction. J Am Chem Soc, 2005, 127: 10723-10730

25 Nakayama Y, Sogo K, Yasuda H, et al. Unique catalytic behavior of chromium complexes having halogenated bis(imino)pyridine ligands for ethylene polymerization. J Polym Sci: Part A: Polym Chem, 2005, 43: 3368-3375

26 Wang Q, Yang H, Fan Z. Efficient activators for an iron catalyst in the polymerization of ethylene. Macromol Rapid Commun, 2002, 23: 639-642

Open Access This article is distributed under the terms of the Creative Commons Attribution License which permits any use, distribution, and reproduction in any medium, provided the original author(s) and source are credited. 